\title{
Laparoscopic Repair of Utero-Peritoneal Fistula; A Fertility Preserving Approach with Subsequent Live Birth
}

\author{
Benjamin P Jones ${ }^{1,2^{*}}$, Abirami Rajamanoharan ${ }^{1}$, Geoffrey Trew ${ }^{2}$ and Alan Farthing ${ }^{1,2}$ \\ ${ }^{1}$ West London Gynaecological Cancer Centre, Hammersmith Hospital, Imperial College NHS Trust, \\ London, UK \\ ${ }^{2}$ Department of Surgery and Cancer, Imperial College London, Du Cane Road, London, UK
}

\begin{abstract}
Case: A 40-year-old woman presented with secondary infertility after surgical management of miscarriage. A hysterosalpingogram (HSG) and magnetic resonance imaging identified a large Caesarean scar defect with fistulation into the peritoneal cavity. She subsequently underwent laparoscopic repair of the uteroperitoneal fistula.

Outcome: A repeat HSG three months post-operatively confirmed successful closure of the fistula. 18 months postoperatively she successfully spontaneously conceived with twins. Despite demise of one twin in early pregnancy, she underwent an uncomplicated Caesarean section at term. At the time of writing, she is three years post-repair, remains asymptomatic, and has now completed her family.

Conclusion: We demonstrate herein an effective laparoscopic surgical repair of a uteroperitoneal fistula and report an excellent clinical outcome including successful live birth. With only 15 cases reported in the literature to date, it is unsurprising there is lack of consensus and little guidance with regards to their management. Following review of the literature, we propose a management algorithm to help guide and facilitate the management of such cases in the future. Given the preponderance to impact women of reproductive age, and the fact that more than a third affected are nulliparous, consideration of fertility sparing surgical techniques is essential.
\end{abstract}

\section{Keywords}

Gynecology, Infertility, Laparoscopy, Surgery, Uterus

\section{Introduction}

In the context of the increasing trend of delivery by Caesarean section [1], awareness and appreciation of the potential associated complications including scar pregnancy [2], low lying and morbidly adherent placenta $[3,4]$ and uterine rupture [5], is essential. Whilst the majority do not suffer such significant sequalae, thinning and indentation of the myometrium at the site of previous hysterotomy is a common occurrence. Up to $61 \%$ of women display ultrasonographic evidence of scar defects after a single caesarean section, with associated increasing rates and worsening severity as the number of Caesarean sections performed rises [6]. Despite this, full thickness defects resulting in the development of uterine fistulas, remains rare. Whereas uterovesical are the commonest sub type, uteroperitoneal fistulas are the rarest, with only 15 cases reported since it was first described in 1872 [7].

The most common predisposing factor in the development of uteroperitoneal fistulas is Caesarean section [8-11], but previous surgical termination of pregnancy (STOP) $[10,12,13]$, myomectomy [14-16] and salpingectomy $[17,18]$ have also been reported. Dysmenorrhoea and sub fertility are the most frequent presentations, with lesser reported symptoms including oligomenorrhoea, intermenstrual bleeding, menorrhagia, pelvic pain and dyspareunia. Imaging modalities most commonly utilised to facilitate the diagnosis include hysterosalpingogram (HSG), magnetic resonance imaging (MRI) and pelvic ultrasound. Management usually necessitates surgical

*Corresponding author: Benjamin P Jones, West London Gynaecological Cancer Centre, Hammersmith Hospital, Imperial College NHS Trust, London, W12 OHS London, UK

Accepted: November 11, 2020

Published online: November 13, 2020

Citation: Jones BP, Rajamanoharan A, Trew G, et al. (2020) Laparoscopic Repair of Utero-Peritoneal Fistula; A Fertility Preserving Approach with Subsequent Live Birth. Annals Gynecol Obstet 4(2):90-96 


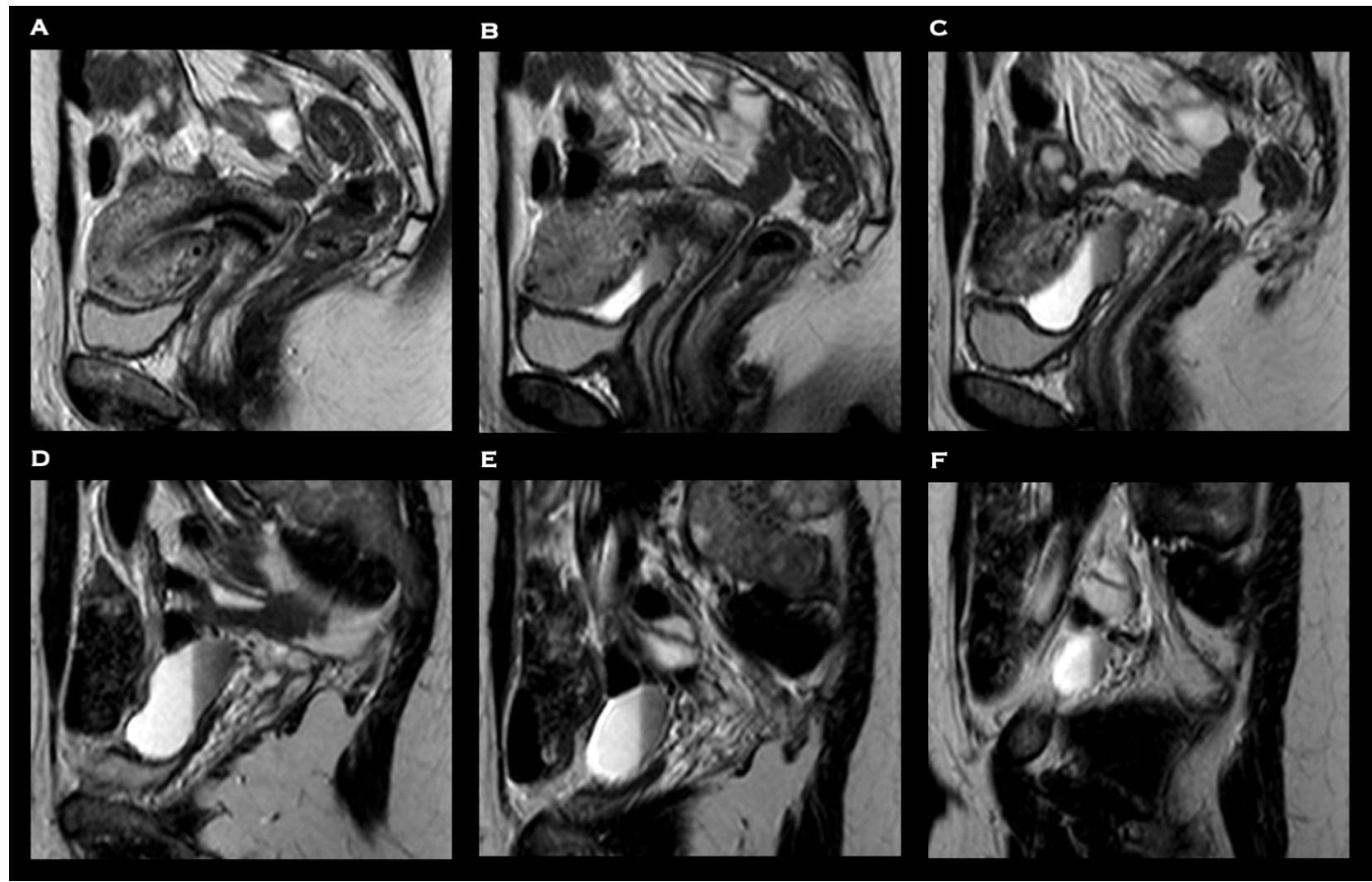

Figure 1: Sagittal magnetic resonance imaging (MRI) of the pelvis demonstrating the presence of a tract extending from the right lateral aspect of the Caesarean section scar into a fluid collection, with signal characteristic consistent with blood.

intervention, with fertility sparing surgical excision and repair of the defect, or hysterectomy in those who have completed their families, or where repair is not possible. Medical management has also been described in a woman who was unsuitable for surgery due to medical comorbidities [11].

We present herein a successful fertility sparing laparoscopic repair of a uteroperitoneal fistula along with subsequent successful conception and achievement of a live birth. We further provide a review of all cases undertaken to date and provide a proposed management algorithm to facilitate the management of this rare entity in future cases.

\section{Case Report}

A 40-year-old woman presented with a 3-year history of secondary infertility. Three years previously she underwent surgical management of miscarriage following her second miscarriage. Post-operative haemorrhage necessitated a return to theatre where she underwent evacuation of retained products of conception and received a blood transfusion. No uterine perforation was noted intraoperatively. She since described a history of light menstrual flow in combination with a feeling of incomplete menstruation and bloating. She did not complain of dysmenorrhea or dyspareunia. She had one child, born by elective Caesarean section, which was undertaken for breach presentation 5 years previously. She was otherwise fit and well with no other previous medical or surgical history.

Examination findings were unremarkable. No biochemical or haematological abnormalities were identified. Pelvic trans- vaginal ultrasound was unremarkable. A HSG was performed which revealed a large Caesarean scar defect with fistulation into the peritoneal cavity. An MRI pelvis was subsequently to further delineate the fistula and exclude bowel involvement. It confirmed the presence of a tract extending from the right lateral aspect of the Caesarean section scar into a peritoneal fluid collection, with signal characteristic consistent with blood, with no evidence of bowel involvement (Figure 1 and Figure 2).

She subsequently underwent diagnostic laparoscopy which confirmed the presence of the defect between the lower segment of the uterus and the retro peritoneum (Figure 3 ). Following mobilisation of the bladder, excision and repair of the uteroperitoneal fistula was undertaken. The surgical technique utilised in this case has been described previously [19]. Following hysteroscopic confirmation of repair, a levonorgestrel-containing intrauterine system (Mirena ${ }^{\circledR}$, Bayer AG, Reading, UK) was inserted. She underwent an uncomplicated post-operative recovery and within three months her symptoms had fully resolved. The Mirena ${ }^{\circledR}$ was removed and HSG confirmed successful closure of the fistula. Six months post-operatively she spontaneously conceived but miscarried during early pregnancy. 18 months post-operatively she successfully spontaneously conceived with twins. Despite demise of one twin in early pregnancy, the remainder of the antenatal period was uneventful, and she underwent an uncomplicated Caesarean section at term. At the time of writing, she is three years post-repair, remains asymptomatic, and has now completed her family. Informed and written consent was ob- 
Citation: Jones BP, Rajamanoharan A, Trew G, et al. (2020) Laparoscopic Repair of Utero-Peritoneal Fistula; A Fertility Preserving Approach with Subsequent Live Birth. Annals Gynecol Obstet 4(2):90-96

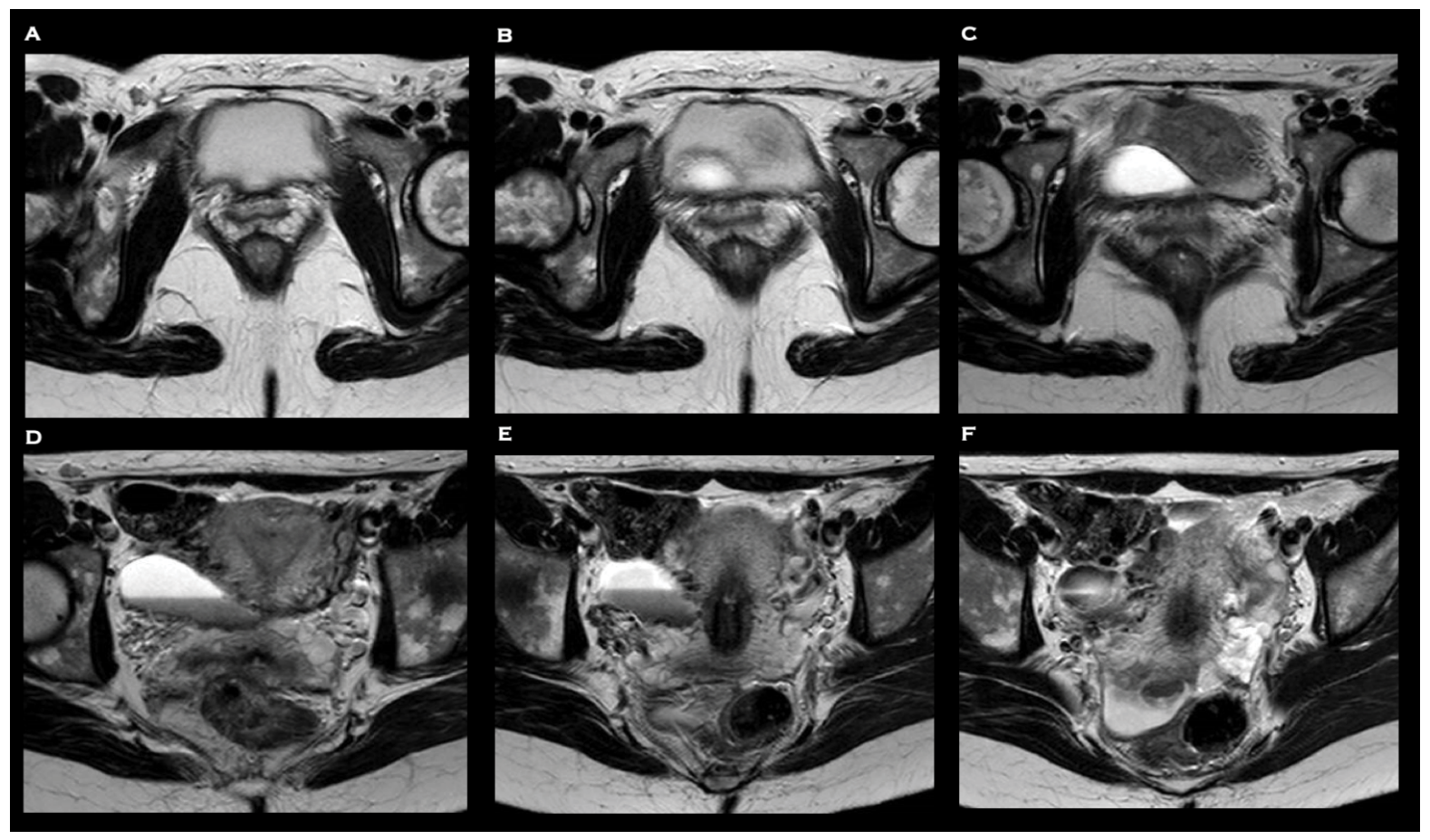

Figure 2: Transverse magnetic resonance imaging (MRI) of the pelvis demonstrating the presence of a tract extending from the right lateral aspect of the Caesarean section scar into a fluid collection, with signal characteristic consistent with blood.

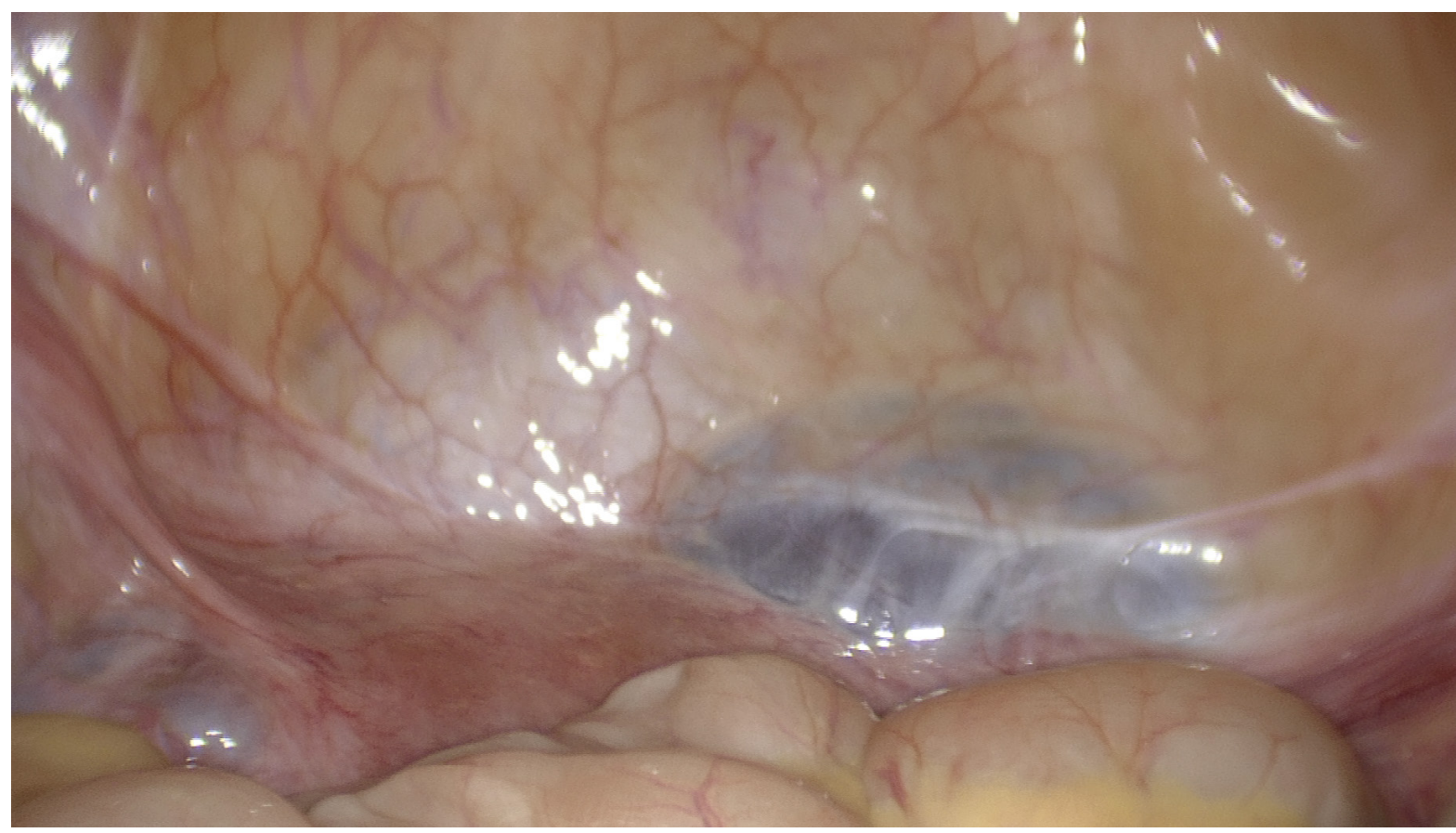

Figure 3: Laparoscopic identification of the uteroperitoneal fistula.

tained from the participant included in the case report

\section{Discussion}

We demonstrate herein a rare case of uteroperitoneal fistula, which was repaired laparoscopically, with clinical resolution of symptoms and the subsequent achievement of a live birth. (Table 1) summarises the 15 cases of uteroperitoneal fistula reported to date. The mean age of women in report- ed cases so far was 31 years old (SD 7.1; Range 17-41), highlighting that this condition almost exclusively affects women of reproductive age. Moreover, more than a third of cases occurred in nulliparous women, highlighting the need to consider fertility sparing surgical techniques where appropriate and possible.

Including our case, previous Caesarean section is the most common predisposing factor, being present in almost half of 


\begin{tabular}{|c|c|c|c|c|c|c|c|c|c|c|c|c|c|c|c|}
\hline 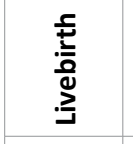 & $\frac{1}{z}$ & 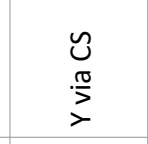 & $\tilde{z}$ & $\tilde{z}$ & $\stackrel{\mathbb{z}}{z}$ & $\stackrel{\mathbb{z}}{z}$ & $\tilde{z}$ & $\tilde{z}$ & $\tilde{z}$ & $\tilde{z}$ & $\tilde{z}$ & $\tilde{z}$ & $\tilde{z}$ & $\tilde{z}$ & $\begin{array}{l}\text { zz } \\
\text { in }\end{array}$ \\
\hline 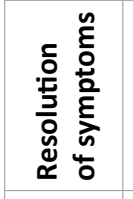 & $\frac{\varangle}{z}$ & $>$ & $\Sigma$ & $\tilde{z}$ & $\frac{\mathbb{z}}{z}$ & $\frac{\mathbb{z}}{\mathbf{z}}$ & $>$ & $>$ & $\Sigma$ & $\Sigma$ & $\Sigma$ & $\tilde{z}$ & $\tilde{z}$ & $>$ & 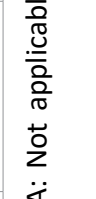 \\
\hline 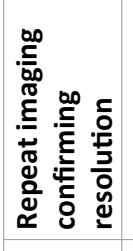 & $\Sigma$ & $\Sigma$ & $\Sigma$ & $>$ & $\Sigma$ & $\Sigma$ & $\Sigma$ & $>$ & $\Sigma$ & $>$ & $\Sigma$ & $\tilde{z}$ & $\tilde{z}$ & $\tilde{z}$ & : \\
\hline 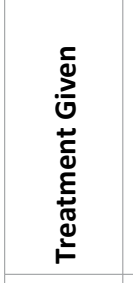 & 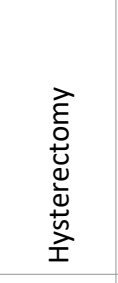 & 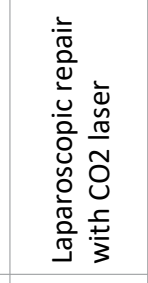 & $\tilde{z}$ & 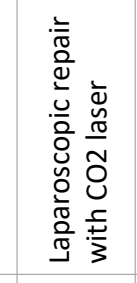 & 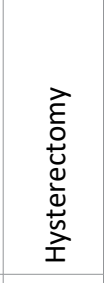 & 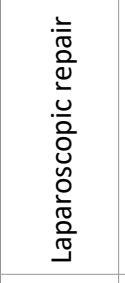 & 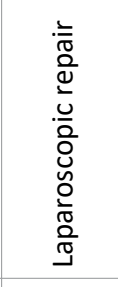 & 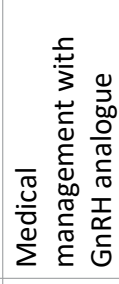 & $\begin{array}{l}\frac{\bar{\pi}}{\overline{0}} \\
\frac{0}{2} \\
\frac{0}{\Phi} \\
\frac{0}{0}\end{array}$ & 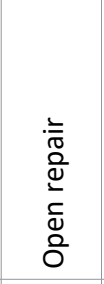 & $\begin{array}{l}\frac{\bar{\pi}}{\overline{0}} \\
\frac{0}{2} \\
\frac{0}{0} \\
\frac{0}{0}\end{array}$ & 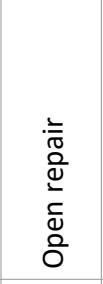 & 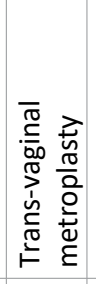 & 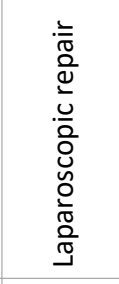 & . \\
\hline 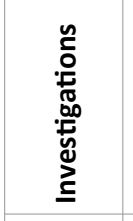 & 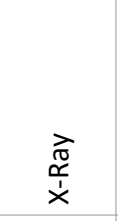 & 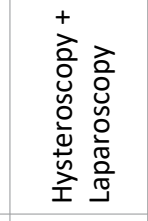 & 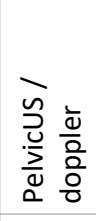 & 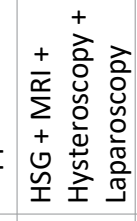 & 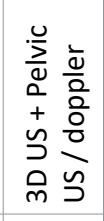 & 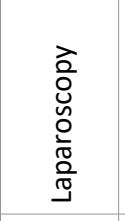 & 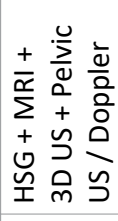 & 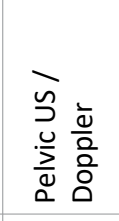 & 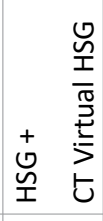 & 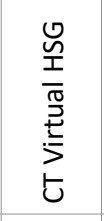 & 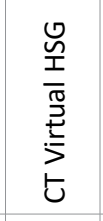 & 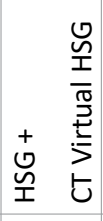 & ญ్ & 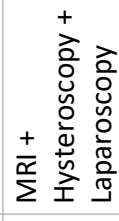 & 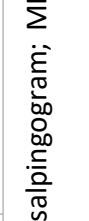 \\
\hline 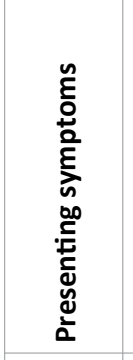 & 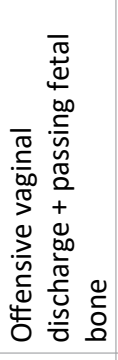 & 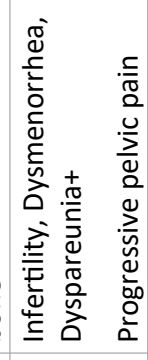 & 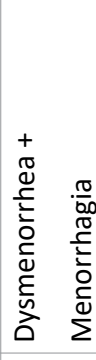 & 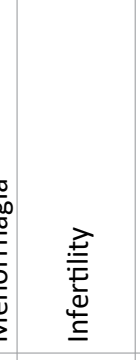 & 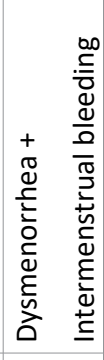 & 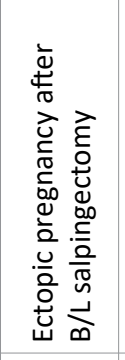 & 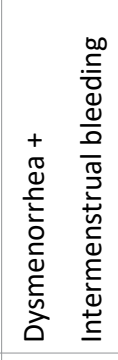 & 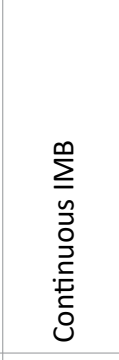 & 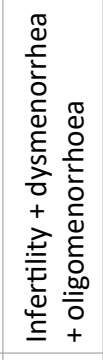 & 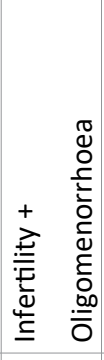 & 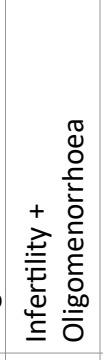 & $\tilde{z}$ & $\tilde{z}$ & 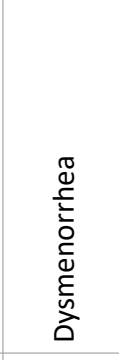 & 跣 \\
\hline 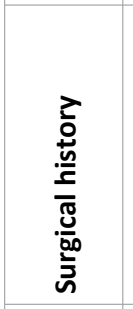 & 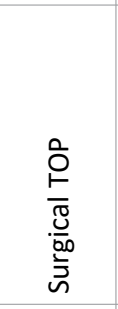 & 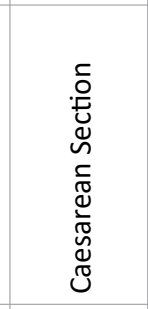 & 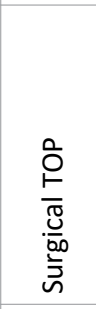 & 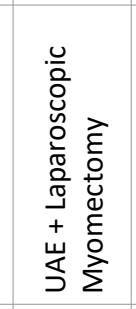 & 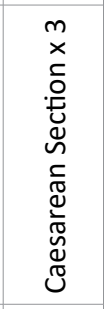 & 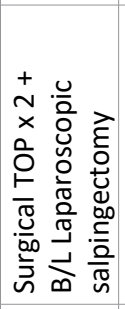 & 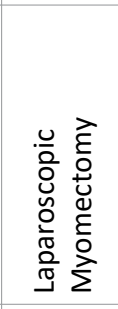 & 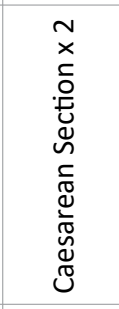 & 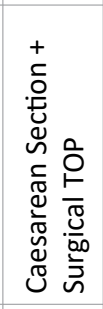 & 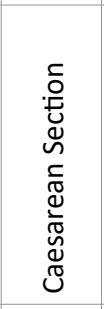 & 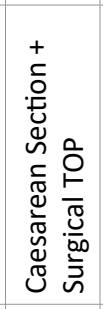 & 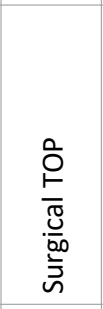 & 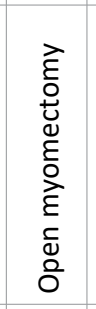 & 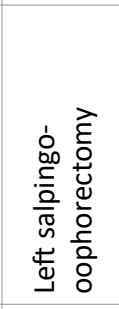 & d \\
\hline 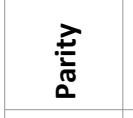 & $\nabla$ & $\neg$ & 0 & 0 & $m$ & $\sim$ & 0 & $m$ & $N$ & -1 & $r$ & 0 & 0 & 0 & \\
\hline 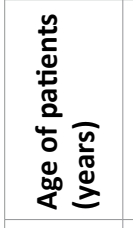 & ○ & $\stackrel{ম}{\sim}$ & $\tilde{m}$ & $\stackrel{\infty}{m}$ & $\stackrel{m}{m}$ & $\vec{N}$ & $\stackrel{m}{m}$ & $\hat{m}$ & $\stackrel{\infty}{m}$ & p & $\vec{\gamma}$ & $\stackrel{\sim}{\mathbf{N}}$ & กี & ન & \\
\hline 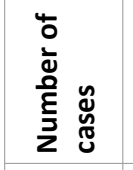 & -1 & -1 & -1 & -1 & -1 & & -1 & 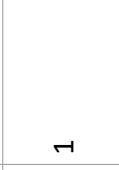 & & 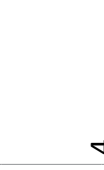 & & & -1 & $\rightarrow$ & \\
\hline 高 & 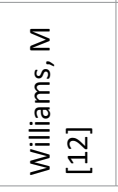 & 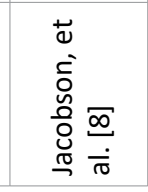 & 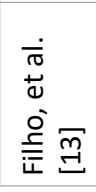 & 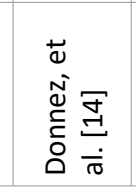 & 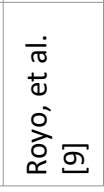 & 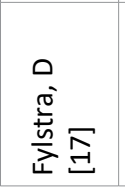 & 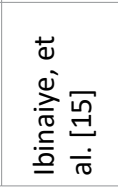 & 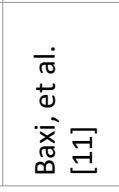 & & $\frac{2}{\pi}$ & & & 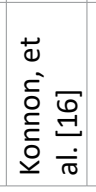 & 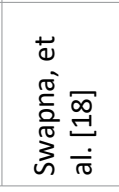 & 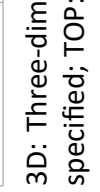 \\
\hline
\end{tabular}


the cases reported to date $(n=7)$ [8-11]. It is therefore unsurprising that the global increasing trend of delivery by lower segment Caesarean section (LSCS) has been associated with an increase in prevalence of uterine fistulas [20]. In our case, whilst the previous LSCS may have created an inherent weakness in the lower uterine segment, as the onset of symptoms and sub fertility started after the two ERPCs, it is likely these provided the additional trauma that precipitated the formation of the fistula. Similarly, traumatic uterine curettage has also been implicated as an aetiology in almost half of the cases reported so far $(n=6)$, albeit following STOP $[10,12,13]$. Four cases were undertaken in criminal circumstances, which introduces the likelihood of questionable sterility and as such raises the possibility of infection potentiating the risk of fistula formation further $[10,12]$. A further case described a uteroperitoneal fistula originating from the right uterine side wall following previous laparoscopic myomectomy which was preceded by uterine artery embolisation (UAE) [14]. It was suggested that the preceding devascularisation associated with UAE may have negatively impacted uterine healing post-myomectomy, which predisposed to fistula formation. UAE is also associated with infection and necrotic fibroids, which could further potentiate the formation of fistulas [14]. Another case reported the presence of a uteroperitoneal fistula formed at a uterine cornu following previous unilateral salpingectomy and proximal salpingectomy after two previous ectopic pregnancies. Despite the previous ligation of both tubes at the cornu, a further ectopic pregnancy arose in the distal remaining Fallopian tube, and a diagnosis of uteroperitoneal fistula was presumed [17].

HSG and MRI can be very effective imaging modalities in the diagnosis of uteroperitoneal fistulas. In other reported cases, the use of HSG, either with conventional x-ray or utilising virtual computed tomography (CT), was used to facilitate the diagnosis in almost half of women $(n=7)$. Despite the ability to accurately delineate where the fistula communicates, the use of MRI has been utilised less frequently, having only been used in a fifth of cases reported to date $(20 \% ; n=$ 3). Whilst the use of ultrasound failed to identify the fistula in our case, it has been used effectively in almost a third of published cases, showing it may be a useful tool in this context. Direct visualisation of the defect, either hysteroscopically $(n=3)$ or laparoscopically $(n=4)$ have also been utilised. Owing to the necessity in this context for anaesthesia, these options are clearly associated with greater risk, and should be reserved, and undertaken at the time of repair.

Regarding management, surgical repair remains the main therapeutic option. Out of the 14 cases where details of treatment are known, 13 underwent surgical intervention. 11 received fertility sparing procedures resulting in excision and repair of the defect, whilst two underwent hysterectomy. The two women who underwent hysterectomy were both multiparous with three and four offspring respectively. In one case, the uterine wall was thin and eroded and not amenable to successful repair, so vaginal hysterectomy was undertaken [12]. Of the 11 fertility sparing cases, almost half were undertaken laparoscopically $(n=5)$, whilst another five were performed through laparotomy, and one was repaired vaginally. One case was medically managed in a 37-year-old woman with significant comorbidities, including multiple previous cardiac surgeries and Hepatitis $C$. Following the diagnosis of a uteroperitoneal fistula using ultrasound, medical management with GNRH analogues for six months resulted in ultrasonographic resolution of the defect and improvement of her symptoms.

HSG can also be effectively used post-operatively to ensure radiological resolution of the defect $[10,14]$. Ensuring the fistula has resolved prior to attempted conception is essential, to reduce the risk of subsequent adverse pregnancy outcomes including abdominal or scar pregnancies. Clinical and reproductive outcomes following uteroperitoneal fistula repair remain scarce. We report herein the second reported live birth following repair of uteroperitoneal fistula, which was delivered by Caesarean section. In the only other reported pregnancy, following laparoscopic repair of the fistulous tract, complete resolution of symptoms was achieved and the subsequent delivery of a live infant was achieved via Caesarean section [8]. In a similar fashion to recommendations following repair of other uterine fistulas, the recommended mode of delivery after repair of uteroperitoneal fistula should be by Caesarean section, [21] to reduce the risk of uterine rupture or recurrence of the fistula after delivery.

In summary, we present herein a successfully managed case of uteroperitoneal fistula which was surgically managed using a minimally invasive and fertility sparing surgical technique. Uteroperitoneal fistulas are a rare cause of sub fertility and pelvic pain, which tend to arise after surgery to the uterus, most frequently during pregnancy, but also following myomectomy or salpingectomy. A proposed management algorithm for the management of such cases is demonstrated in (Figure 4). Whilst they may be diagnosed following routine HSG for investigation of sub fertility, HSG remains an excellent diagnostic modality that should be performed on clinical suspicion of uterine fistulas. MRI should be used to more accurately delineate the extent of the fistula, including the localisation of which surfaces are communicating. Given the preponderance to impact women of reproductive age, and the fact that more than a third affected are nulliparous, consideration of fertility sparing surgical techniques is essential. This is particularly important in the context of the recent and ongoing trend of women delaying their childbearing years, which has led to a rise in age of first-time motherhood.

\section{Acknowledgements}

Nil.

\section{Disclosures}

\section{Conflict of interest}

Benjamin P Jones, Abirami Rajamanoharan, Geoffrey Trew and Alan Farthing. Declare no conflict of interest.

\section{Human rights statement and informed consent}

The authors obtained signed consent from the patient to publish the information. 
Citation: Jones BP, Rajamanoharan A, Trew G, et al. (2020) Laparoscopic Repair of Utero-Peritoneal Fistula; A Fertility Preserving Approach with Subsequent Live Birth. Annals Gynecol Obstet 4(2):90-96

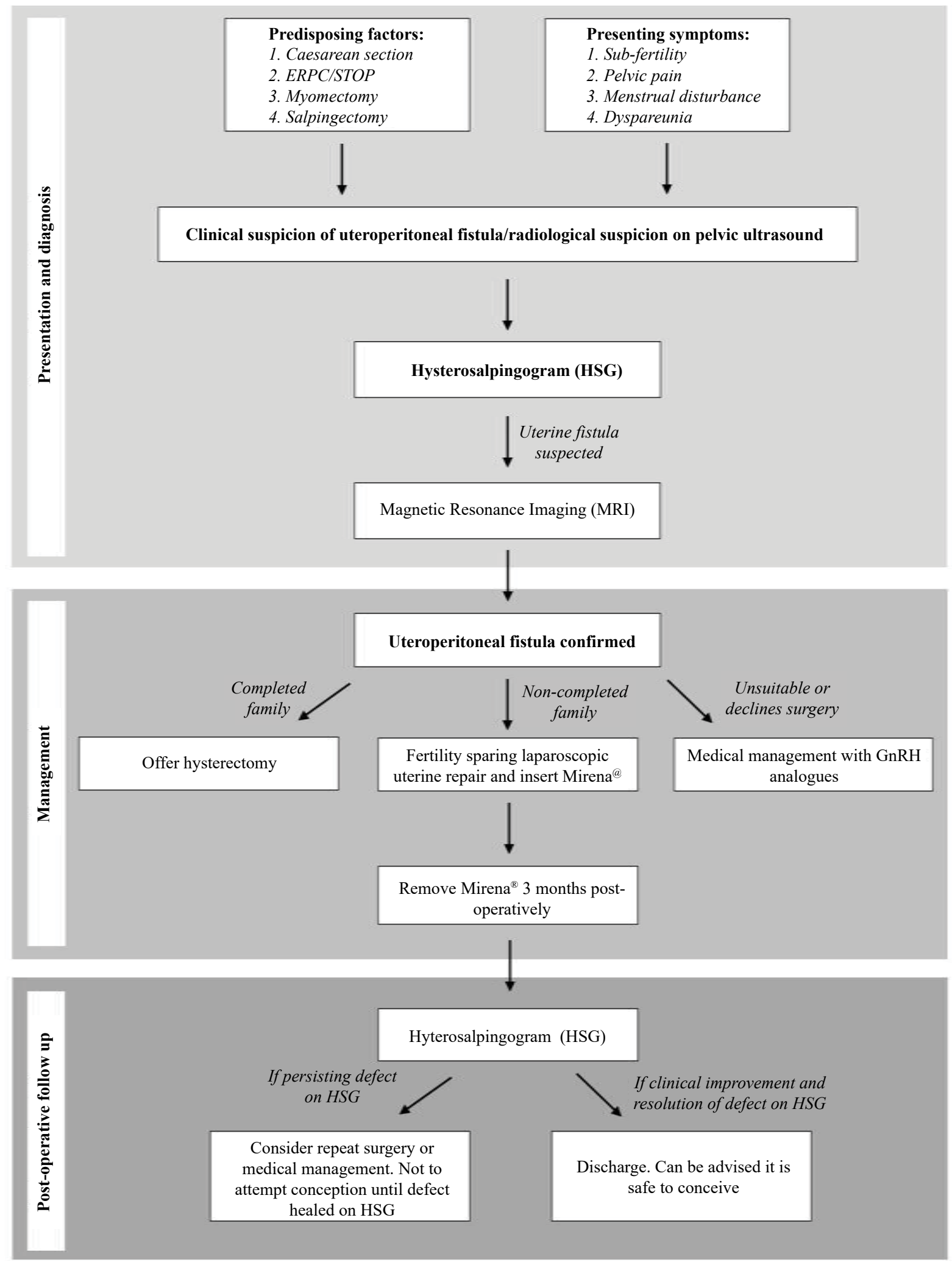

ERPC; Evacuation of retained product of conception LSCS; lower section Caesarean section, GnRH; Gonadotrophin releasing hormone

Figure 4: Suggested management algorithm for the management of uteroperitoneal fistulas.

\section{Human/Animal studies}

This article does not contain any studies with human and animal subjects performed by any of the authors.

\section{References}

1. Notzon FC, Placek PJ, Taffel SM (1987) Comparisons of national cesarean-section rates. N Engl J Med 316: 386-389. 
Citation: Jones BP, Rajamanoharan A, Trew G, et al. (2020) Laparoscopic Repair of Utero-Peritoneal Fistula; A Fertility Preserving Approach with Subsequent Live Birth. Annals Gynecol Obstet 4(2):90-96

2. Jurkovic D, Hillaby K, Woelfer B, et al. (2003) First-trimester diagnosis and management of pregnancies implanted into the lower uterine segment cesarean section scar. Ultrasound Obstet Gynecol 21: 220-227.

3. Getahun D, Oyelese Y, Salihu HM, et al. (2006) Previous cesarean delivery and risks of placenta previa and placental abruption. Obstet Gynecol 107: 771-778.

4. Ben Nagi J, Ofili-Yebovi D, Marsh M, et al. (2005) First-trimester cesarean scar pregnancy evolving into placenta previa/accreta at term. J Ultrasound Med 24: 1569-1573.

5. Guise JM, McDonagh MS, Osterweil P, et al. (2004) Systematic review of the incidence and consequences of uterine rupture in women with previous caesarean section. BMJ 329: 19-25.

6. Osser OV, Jokubkiene L, Valentin, L (2009) High prevalence of defects in cesarean section scars at transvaginal ultrasound examination. Ultrasound Obstet Gynecol 34: 90-97.

7. Tait L (1872) Utero-peritoneal fistula. The Lancet 100: 557-558.

8. Jacobson MT, Osias J, Velasco A, et al. (2003) Laparoscopic repair of a uteroperitoneal fistula. JSLS 7: 367-369.

9. Royo P, Manero MG, Olartecoechea B, et al. (2009) Two-dimensional power Doppler-three-dimensional ultrasound imaging of a cesarean section dehiscence with utero-peritoneal fistula: $A$ case report. J Med Case Rep 3: 42.

10. Nouraly H, Toure A, Horo A, et al. (2015) Interest of multidetector CT virtual hysterosalpingography in the diagnosis of utero-peritoneal fistulas about 4 cases. J Gynecol Obstet Biol Reprod (Paris) 44: 93-96.

11. Baxi LV, Lerner JP, Nova J (2015) Symptomatic chronic uterine dehiscence: A different approach, non-surgical successful closure. J Obstet Gynaecol India 65: 56-59.
12. Williams M (1946) Abdominal skeletonized fetus with uteroperitoneal fistula secondary to criminal abortion. Am J Surg 72: 750-752.

13. Guimaraes Filho HA, da Costa LL, Araujo E, et al. (2007) Diagnosis of uteroperitoneal fistula through color Doppler hysterosonography. Arch Gynecol Obstet 276: 85-86.

14. Donnez O, Jadoul P, Squifflet J, et al. (2008) Unusual complication after uterine artery embolization and laparoscopic myomectomy in a woman wishing to preserve future fertility. Fertil Steril 90: e5-e9.

15. Ibinaiye PO, Onwuhafua P, Usman B (2013) Utero-peritoneal fistula, a rare complication of laparoscopic myomectomy scar dehiscence: A case Report. Niger Postgrad Med J 20: 165-166.

16. Konnon SR, Shalaev ON, Shmanaeva II, et al. (2016) An interesting case of metroplasty in utero-peritoneal fistula by vaginal access. RUDN Journal of Medicine 98-102.

17. Fylstra DL (2009) Uteroperitoneal fistula formation after proximal salpingectomy with harmonic scalpel resulting in a third consecutive fallopian tube ectopic pregnancy: A case report. J Reprod Med 54: 330-332.

18. Swapna YK, Yelamanchi SD, Talipineni KN, et al. (2018) A rare case of utero peritoneal fistula. International Journal of Reproduction, Contraception, Obstetrics and Gynecology 7.

19. Jones BP, Rajamanoharan A, Trew G, et al. (2019) Laparoscopic repair of utero-peritoneal fistula. Journal of Minimally Invasive Gynecology.

20. Porcaro AB, Zicari M, Zecchini Antoniolli S, et al. (2002) Vesicouterine fistulas following cesarean section: Report on a case, review and update of the literature. Int Urol Nephrol 34: 335-344.

21. Yip SK, Leung TY (1998) Vesicouterine fistula: An updated review. Int Urogynecol J Pelvic Floor Dysfunct 9: 252-256.

DOI: $10.36959 / 468 / 473$

Copyright: (c) 2020 Jones BP, et al. This is an open-access article distributed under the terms of the Creative Commons Attribution License, which permits unrestricted use, distribution, and reproduction in any medium, provided the original author and source are credited. 